\title{
Colour Doppler-an evaluation tool for assessment of breast tumour size, axillary lymph node size and chemotherapeutic response
}

\author{
Rashmi Singh ${ }^{1}$, Govardhan H. B. ${ }^{1}$, Satyajt $\operatorname{Pradhan}^{1}$, Anand Kumar ${ }^{2}$, R. C. Shukla ${ }^{3}$, U. P. Shahi ${ }^{1}$, \\ L. M. Agrawal ${ }^{1}$ \\ ${ }^{1}$ Departments of Radiotherapy and Radiation Medicine, Institute of Medical Sciences, Banaras Hindu University, Varanasi, India \\ ${ }^{2}$ Departments of Surgery, Institute of Medical Sciences, Banaras Hindu University, Varanasi, India \\ ${ }^{3}$ Department of Radiodiagnosis \& Imaging, Institute of Medical Sciences, Banaras Hindu University, Varanasi, India
}

\section{Email address:}

hbgovardhan@yahoo.co.in (Govardhan H. B.)

\section{To cite this article:}

Rashmi Singh, Govardhan H. B., Satyajt Pradhan, Anand Kumar, R. C. Shukla, U. P. Shahi, L. M. Agrawal. Colour Doppler-An Evaluation Tool for Assessment of Breast Tumour Size, Axillary Lymph Node Size and Chemotherapeutic Response. Journal of Cancer Treatment and Research. Vol. 2, No. 2, 2014, pp. 9-15. doi: 10.11648/j.jctr.20140202.11

\begin{abstract}
Aims: The present study was taken up in carcinoma breast patients to evaluate clinical examination and Colour Doppler in estimating the breast tumour size, axillary lymph node size and chemotherapeutic response, taking histopathological examination as the gold standard. Material \& Methods: The study carried out between December 2008 to June 2010 included 37 patients. Ethics committee clearance obtained. Chemotherapeutic response could be assessed in 24 patients who received chemotherapy prior to surgery. 13 patients were taken up directly for surgery. Clinical, sonological and histopathological largest dimension of the primary tumour and axillary lymph nodes were assessed. Chemotherapy response grades were assessed as per criteria given by Kumar A et al. Results were analyzed using paired-t test, weighted kappa and Spearman correlation coefficient. Results: The difference between mean clinical and histopathological size of breast tumour of $0.01 \mathrm{~cm}$, was statistically not significant $(\mathrm{t}=.064, \mathrm{p}=.949)$. However, the difference between mean sonological and histopathological size of breast tumour of $1.10 \mathrm{~cm}$, was statistically highly significant $(\mathrm{t}=-3.93, \mathrm{p}<.001)$. For axillary lymph nodes, the mean difference between clinical and histopathological assessment was $0.46 \mathrm{~cm}$ ( $\mathrm{p}=0.007)$ as against mean difference of $0.48 \mathrm{~cm}$ between sonological and histopathological assessment $(\mathrm{p}=0.001)$. Clinical response showed substantial agreement with histopathological response in breast tumour $(\mathrm{k}=0.657 ; \mathrm{p}=0.001)$ and axillary lymph nodes $(\mathrm{k}=0.62 ; \mathrm{p}<0.005)$. Sonological response showed moderate agreement $(\mathrm{k}=0.510 ; \mathrm{p}<0.02)$ in breast tumour and substantial agreement $(\mathrm{k}=0.691$; $\mathrm{p}<0.001)$ in axillary lymph nodes. Compared to histopathological response, RI, PI and Vmax response showed moderate agreement in primary and substantial agreement in axillary lymph nodes. Conclusion: In the present study, sonology was found to be a poor modality for breast tumour size, axillary lymph node size estimation. With regard to chemotherapy response assessment, clinical examination was a better modality for primary, while Colour Doppler was better for axillary lymph node evaluation.
\end{abstract}

Keywords: Colour Doppler, Chemotherapeutic Response, Breast Cancer

\section{Introduction}

The size of a malignant breast tumour is an important prognostic factor for the survival of breast cancer patients [14], and a determinant in the T-classification of the TNM system [5]. The clinical tumour (cT-) stage is assessed by physical examination and imaging. The measurement should be performed by the method 'judged most accurate' [5]. At present most clinicians and reports use pT-staging, as this tumour size will remain the reference standard [6].

Neoadjuvant chemotherapy has become an established part of treatment of stage II and III breast cancer. Chemoresponsive tumors have a better overall survival than nonresponders [7]. About 20 to $30 \%$ of advanced breast cancer (ABCs) show either no or poor response to chemotherapy [8, 9]. For this subgroup of patients, early prediction of tumor response to neoadjuvant chemotherapy is desirable. By 
avoiding ineffective chemotherapy and reducing advanced surgery, the treatment will be more cost-effective in such cases where the overall outlook is intrinsically bad.

Clinical examination of the breast has to date been the most widely used approach for response assessment, having the advantages of being simple, quick, easy and non-invasive. However, this method varies among observers, is influenced by many factors such as skin thickness, edema and obesity [10, 11] and could result in overestimation of tumour size [12].

Tumor vascularity is a surrogate marker of tumor burden and this can be readily assessed by color Doppler ultrasound using various indices (resistivity index, pulsatility index and maximum flow velocity). The pre- and post-chemotherapy indices can be compared to assess the response to chemotherapy. Among various imaging modalities, MRI and PET have the highest sensitivity in detecting the tumor response, but they are not cost effective. Doppler US allows both a morphological study of tumors and an accurate analysis of tumor vascularity. With Doppler sonography, tumor vascularity can be assessed in vivo [13]. Color Doppler ultrasound is a promising alternative for tumor response assessment owing to its availability, reproducibility and cost-effectiveness [14].

The present study in carcinoma breast patients using Colour Doppler as an evaluation tool was taken up to test the accuracy of clinical examination and colour Doppler, taking measurement on histopathological examination as the standard in estimating the breast tumour size, axillary lymph nodes size and chemotherapeutic response.

\section{Material and Methods}

Thirty seven histopathologically proven cases of carcinoma breast were studied between December 2008 to June 2010. Patients who had received any chemotherapy/ Surgery/Radiotherapy prior to the study were not included in the study. The Institute postgraduate research board and the departmental research committee have approved the study and the informed written consent of the subjects was recorded individually on the case records. Twenty four patients received neoadjuvant chemotherapy (CAF) and chemotherapeutic response was assessed in them and 13 patients were taken up directly for modified radical mastectomy. Clinical measurement of the breast tumour and axillary lymph nodes were done using vernier calipers, taking two perpendicular diameters. Mean diameter and Volume $\left(\pi / 6 \mathrm{xd}^{3} ; \mathrm{d}=\right.$ mean diameter in centimeters) were calculated.

Color Doppler examination of the tumor was done using LOGIQ 400 CL System (GE medical system) with a LA 39, $11 \mathrm{MHz}$ probe. Ultrasound examination was performed by a single experienced sonologist who was blinded to the patients' clinical profile, treatment history, response status and the pre chemotherapy findings. Normal and B-mode images were taken to define the tumour margin. The scan was done in multiple planes to include whole of the breast and axilla. The probe was held orthogonal to the skin and moved over the tumour till maximum diameter was demonstrated. Two measurements were made perpendicular to each other and the thickness of the lesion was recorded using the electronic calipers. Sonographic tumour volume $\left(\mathrm{Vs}=\pi / 6 \times \mathrm{d}_{1} \times \mathrm{d}_{2} \times \mathrm{D}\right)$ was calculated using the formula for the volume of the ellipsoid, where, $d_{1}, d_{2}$ are diameters of the tumour in centimeters and D is depth of the tumour in centimeter. Standardised machine setting were used to optimise sensitivity to low velocity and low volume blood flow. PI i.e. (Peak flow velocity - End diastolic velocity)/average velocity, RI i.e. (Peak systolic velocity End diastolic velocity)/Peak systolic velocity and Vmax were measured. Clinical and sonological chemotherapeutic response in the breast tumour and axillary lymph nodes were aseessed by observing the percentage change in volume for breast tumour and change in maximum dimension for axillary lymph nodes. Percentage change in RI, PI and Vmax in breast tumour and axillary lymph nodes were noted by colour Doppler. Chemotherapeutic response were graded as $1-4$ for $<25 \%, 25-50 \%,>50 \%$ and complete disappearance of tumour, RI, PI and Vmax respectively $[15,16]$. The Doppler Score for breast tumour and axillary lymph nodes were calculated separately by adding the different RI, PI and Vmax grades [15, 16]. The resected specimens were examined histopathologically and the clinical and sonological size were compared with the histopathological size. Histopathologically chemotherapy response was graded as 1-4 for no, minimal, moderate chemotherapeutic change and total annihilation of tumour (100\% disappearance) respectively $[15,16]$. Clinical, sonological and colour Doppler chemotherapeutic response grades were correlated with histopathologicaal response grades. Results were analyzed using paired-t test, weighted kappa and Spearman correlation coefficient.

\section{Results}

Mean age of the patients was $45.10 \pm 11.32 \mathrm{yrs}$, (range 25 $80 \mathrm{yrs})$. T4b status was seen in majority (56.8) \% of the patients and $86.5 \%$ of the patients had N1 status. Clinical size of breast tumour matched the histopathological size in $27.03 \%$ patients. Clinical examination overestimated the breast tumour size in $45.54 \%$ patients and underestimated it in $32.43 \%$ patients. Overestimation and underestimation in size was by $0.51-1 \mathrm{~cm}$ in majority of the patients $(40.0 \%$ and $57.14 \%$ ). Sonological size of breast tumour matched the histopathological size in none of the patients. Sonology overestimated the breast tumour size in $18.92 \%$ patients and underestimated it in $81.08 \%$ patients. Overestimation and underestimation was by $>1 \mathrm{~cm}$ in majority of the patients $(57.14 \%$ and $66.67 \%)$. Clinical size of axillary lymph node matched the histopathological size in $19.44 \%$ patients. Clinical examination overestimated axillary lymph node size in $27.78 \%$ patients and underestimated it in $52.78 \%$ patients. In majority of the patients overestimation in size was by $\leq 0.5 \mathrm{~cm}$ and underestimation was by $>1 \mathrm{~cm}$ (60.0\% and $47.37 \%$ respectively). Sonological size of axillary lymph node matched the histopathological size in 
none of the patients. Sonology overestimated axillary lymph node size in $27.78 \%$ patients and underestimated it in $72.22 \%$ patients. In majority $(70 \%)$ of the patients, sonological examination overestimated the axillary lymph node size by $\leq 0.5 \mathrm{~cm}$. In majority $(42.31 \%)$ of the patients, the underestimation was by $0.51-1 \mathrm{~cm}$.

The statistical analysis results for breast tumour size and axillary lymph node size estimation by clinical examination and sonology against histopathological size has been shown in Table-1. For breast tumour, the difference in the mean size between clinical and histopathological method was $0.01 \mathrm{~cm}$, while the difference in the mean size between sonological and histopathological method was $1.10 \mathrm{~cm}$. Clinical examination overestimated the breast tumour size, but the difference was not statistically significant $(\mathrm{t}=.064$, $\mathrm{p}=.949)$. However, sonology underestimated the breast tumour size and the difference was statistically highly significant $(\mathrm{t}=-3.93, \mathrm{p}=<.001)$.

For axillary lymph nodes, the difference in the mean size between clinical and histopathological method was $0.46 \mathrm{~cm}$, while the difference in the mean size between sonological and histopathological method was $0.48 \mathrm{~cm}$. Both clinical examination and sonology underestimated the axillary lymph node size while considering histopathological examination as the gold standard, but the difference with clinical method is less significant than sonology $(\mathrm{t}=-2.84$, $\mathrm{p}=.007 \mathrm{Vs} \mathrm{t}=-3.45, \mathrm{p}=.001$ ).

A strong correlation with pathological tumour size was observed for primary tumour size estimated by clinical method $(\mathrm{n}=37, \mathrm{r}=.719, \mathrm{p}=<.001)$, while moderate correlation was found for sonology $(r=0.601 ; p=<.001)$. For axillary lymph nodes, a moderate correlation $(\mathrm{r}=.536$, $\mathrm{p}=.001)$ with pathological axillary lymph node size was observed for size estimated by clinical method, while strong correlation $(r=.652$, $p<0.001)$ was seen for sonology

Clinically, the mean largest diameter of breast tumour before chemotherapy was $7.68 \pm 2.54 \mathrm{cms}$ and following chemotherapy it was $4.85 \pm 1.50 \mathrm{cms}$, the mean volume of the breast tumour before and after chemotherapy were $241.72 \pm 318.76 \mathrm{~cm}^{3}\left(22.46-1596 \mathrm{~cm}^{3}\right)$ and 61.03 \pm 62.64 $\mathrm{cm}^{3}\left(8.18-268.19 \mathrm{~cm}^{3}\right)$ respectively. By Colour Doppler examination, the largest mean diameter of the breast tumor before chemotherapy was $5.50 \pm 3.10 \mathrm{cms}(2.40-17.60 \mathrm{~cm})$ and following chemotherapy, it was $3.84 \pm 2.01 \mathrm{cms}(1.0-$ $10.30 \mathrm{cms}$ ) and the mean volume before and after chemotherapy were $110.36 \pm 244.62 \mathrm{~cm}^{3}\left(4.90-1102.10 \mathrm{~cm}^{3}\right)$ and $37.92 \pm 106.75 \mathrm{~cm}^{3}\left(2.97-530 \mathrm{~cm}^{3}\right)$ respectively. Clinical and sonological grades of response in breast tumour volume has been shown in Table-2. Majority of the patients had Grade 3 response both clinically and sonologically. The agreement between clinical and sonological response with histopathological response in breast tumour has been shown in Table-3.

For breast tumour, as substantial agreement has been found between clinical and histopathological response $(\mathrm{k}=0.657 ; \mathrm{p}=0.001)$, while moderate agreement $(\mathrm{k}=0.510$; $\mathrm{p}<0.02$ ) has been found between sonological and histopathological response, it is evident that higher level of agreement for assessing response has been observed by clinical method than sonology $(\mathrm{k}=0.657 ; \mathrm{p}=0.001 \mathrm{Vs}$ $\mathrm{k}=0.510 ; \mathrm{p}<0.02)$.

The clinical mean longest diameter of axillary lymph nodes before and after chemotherapy were $2.64 \pm 0.97 \mathrm{~cm}$ $(1-5 \mathrm{~cm})$ and $1.27 \pm 1.07 \mathrm{~cm}(0-3 \mathrm{~cm})$ respectively. The sonological mean longest diameter of axillary lymph nodes before and after chemotherapy were $2.06 \pm 0.98 \mathrm{~cm}(0.76-$ $3.2 \mathrm{~cm})$ and $1.34 \pm 0.98 \mathrm{~cm}(0-4.3 \mathrm{~cm})$ respectively. Clinical and sonological grades of response in longest diameter of axillary lymph nodes has been shown in Table-2. Majority of the patients had Grade 2 response both clinically and sonologically. Grade 4 response was observed in axillary lymph nodes both clinically and sonologically. The agreement between clinical and sonological response with histopathological response in axillary lymph nodes has been shown in Table-3.

For axillary lymph nodes, substantial agreement $(\mathrm{k}=0.691 ; \mathrm{p}=<0.001)$ has been found between sonological and histopathological response and also substantial agreement $(\mathrm{k}=0.62 ; \mathrm{p}=<0.005)$ has been found between clinical and histopathological response. However, with sonological examination, agreement is more significant than with clinical examination $(\mathrm{p}=<0.001$ vs $\mathrm{p}<0.005)$.

In breast tumour, before chemotherapy the mean value of RI, PI and Vmax were $0.82 \pm 0.25,1.9 \pm 0.9$ and $22.13 \pm 15.15 \mathrm{~cm} / \mathrm{s}$ respectively. After chemotherapy, the mean value of RI, PI and Vmax were $0.90 \pm 0.22,2.32 \pm 2.27$ and $22.13 \pm 15.15 \mathrm{~cm} / \mathrm{s}$ respectively. RI increased (mean $0.29 \pm 0.28$ ) in 12 patients, PI increased (mean $1.33 \pm 2.64$ ) in 14 patients and Vmax increased (mean 8.02 \pm 5.01 ) in 8 patients. In axillary lymph nodes, before chemotherapy the mean value of RI, PI and Vmax were $0.84 \pm 1.79,2.09 \pm 1.17$ and $19.72 \pm 11.24 \mathrm{~cm} / \mathrm{s}$ respectively. After chemotherapy, the mean value of RI, PI and Vmax were $0.58 \pm 0.43,1.27 \pm 1.27$ and $11.03 \pm 11.27 \mathrm{~cm} / \mathrm{s}$ respectively. RI increased $(0.14 \pm 0.11)$ in 8 patients, PI increased $(1.39 \pm 1.26)$ in 5 patients and Vmax increased $(12.23 \pm 2.12 \mathrm{~cm} / \mathrm{s})$ in 3 patients. Grades of RI, PI and Vmax response for breast tumour and axillary lymph nodes has been shown in Table-4.

The agreement between RI, PI and Vmax response with histopathological response in breast tumour and axillary lymph nodes has been shown in Table-3. A moderate agreement $(\mathrm{k}=0.489 ; \mathrm{p}=<0.02)$ has been found between RI response and histopathological response in breast tumour, while substantial agreement $(\mathrm{k}=0.622 ; \mathrm{p}<0.005)$ has been found between RI response and histopathological response in axillary lymph nodes. Like wise for PI and Vmax response, also a moderate agreement with histopathological response has been found for breast tumour, while substantial agreement has been found for axillary lymph nodes. The agreement between Doppler score and histopathology response was found to be moderate in breast tumour as well as in axillary lymph node. However, it was more significant in axillary lymph nodes $(\mathrm{k}=0.562, \mathrm{p}<0.01 ; \mathrm{k}=0.469, \mathrm{p}<0.05)$.

Moderate positive correlation was observed between the 
percentage change in RI and percentage change in sonological axillary lymph node size, i.e. greater the shrinkage of the tumor with chemotherapy, the lower the RI $(\mathrm{r}=0.468, \mathrm{p}=0.021)$. This correlation was not observed ( $\mathrm{r}$ $=-.273, \mathrm{p}=.208)$ in breast tumour.

Table 1. Clinical, Sonological breast tumour size and axillary lymph node size tested against respective Histopathological size.

\begin{tabular}{|c|c|c|c|c|c|c|c|c|c|c|}
\hline & \multicolumn{2}{|c|}{ Mean difference $(\mathrm{cm})$} & \multicolumn{2}{|c|}{ t value } & \multicolumn{2}{|c|}{$p$ value } & \multicolumn{2}{|l|}{$\mathbf{r}$} & \multicolumn{2}{|c|}{$p$ value } \\
\hline & $\mathbf{C L}$ & $\mathbf{S}$ & CL & $\mathbf{S}$ & CL & $\mathbf{S}$ & CL & $\mathbf{S}$ & CL & $\mathbf{S}$ \\
\hline BT & .01 & -1.10 & .064 & -3.93 & .949 & .000 & .719 & .601 & .000 & .000 \\
\hline AXLN & -.46 & -0.48 & -2.84 & -3.45 & .007 & .001 & .536 & .652 & .001 & .000 \\
\hline
\end{tabular}

BT- Breast tumour; AXLN- Axillary lymph node; CL- Clinical; S- Sonological

Table 2. Distribution of Clinical, Sonological and Histopathological response grades in breast tumour and axillary lymph nodes.

\begin{tabular}{|c|c|c|c|c|c|c|}
\hline \multirow[t]{2}{*}{ Grades } & \multirow{2}{*}{$\begin{array}{l}\text { Clinical } \\
\text { BT }\end{array}$} & \multirow[b]{2}{*}{ AXLN } & \multicolumn{2}{|l|}{ Sonology } & \multicolumn{2}{|l|}{ HPE } \\
\hline & & & BT & AXLN & BT & AXLN \\
\hline 1 & $4.16 \%$ & $13.64 \%$ & $25.0 \%$ & $33.3 \%$ & $41.0 \%$ & $30 \%$ \\
\hline 2 & $37.50 \%$ & $45.45 \%$ & $16.67 \%$ & $50.0 \%$ & $12.5 \%$ & $25 \%$ \\
\hline 3 & $58.34 \%$ & $9.09 \%$ & $58.33 \%$ & $0 \%$ & $45.8 \%$ & $45.0 \%$ \\
\hline 4 & $0 \%$ & $31.82 \%$ & $0 \%$ & $16.67 \%$ & $0 \%$ & $0 \%$ \\
\hline
\end{tabular}

BT- Breast tumour; AXLN- Axillary lymph node

Table 3. Breast tumour and axillary lymph nodes: Clinical, Sonological, RI, PI and Vmax response grades agreement with Histopathological response grades.

\begin{tabular}{llllll}
\hline & Clinical & Sonological & Colour Doppler & \\
& & & RI & PI \\
\hline Breast tumour & $(\mathrm{k}=0.62 ; \mathrm{p}=<0.005)$ & $(\mathrm{k}=0.510 ; \mathrm{p}=<0.02)$ & $(\mathrm{k}=0.489 ; \mathrm{p}=<0.02)$ & $(\mathrm{k}=0.510 ; \mathrm{p}=<0.02)$ \\
Axillary LN & $(\mathrm{k}=0.62 ; \mathrm{p}=<0.005)$ & $(\mathrm{k}=0.691 ; \mathrm{p}=<0.001)$ & $(\mathrm{k}=0.622 ; \mathrm{p}=<0.005)$ & $(\mathrm{k}=0.623 ; \mathrm{p}=<0.01)$ & $(\mathrm{k}=0.606 ; \mathrm{p}=<0.005)$ \\
\hline
\end{tabular}

Table 4. RI, PI and Vmax response grades in breast tumour and axillary lymph nodes

\begin{tabular}{|c|c|c|c|c|c|c|}
\hline \multirow{3}{*}{ Grades } & \multicolumn{6}{|c|}{ Colour Doppler } \\
\hline & \multicolumn{3}{|c|}{ BT } & \multicolumn{3}{|c|}{ AXLN } \\
\hline & RI & PI & Vmax & RI & PI & Vmax \\
\hline 1 & $95.84 \%$ & $75 \%$ & $50.0 \%$ & $50.0 \%$ & $29.17 \%$ & $33.33 \%$ \\
\hline 2 & $4.16 \%$ & $16.67 \%$ & $20.83 \%$ & $16.67 \%$ & $29.17 \%$ & $25.0 \%$ \\
\hline 3 & $0 \%$ & $8.33 \%$ & $29.17 \%$ & $4.16 \%$ & $12.50 \%$ & $12.50 \%$ \\
\hline 4 & $0 \%$ & $0 \%$ & $0 \%$ & $29.17 \%$ & $29.17 \%$ & $29.17 \%$ \\
\hline
\end{tabular}

BT- Breast tumour; AXLN- Axillary lymph node

\section{Discussion}

Breast cancer is the most prevalent cancer of women worldwide. The estimated incidence of cancer in India is 800,000 cases and prevalence is about two million cases. About 25\% increase is expected by the year 2015 [17].

Tumor size is one of the most powerful predictors of tumor behavior in breast cancer [4, 18]. The size of the primary tumour ranks among the strongest predictor of distant metastases, disease-free and overall survival. Survival rates varied from $45.5 \%$ for tumor diameters equal to or greater than $5 \mathrm{~cm}$ with positive axillary nodes to $96.3 \%$ for tumors less than $2 \mathrm{~cm}$ and with no involved nodes [4].

In the present study, clinical examination overestimated breast tumour size in $45.54 \%$ patients and underestimated in $32.43 \%$ patients. Sonological examination of breast tumour overestimated the size in $18.92 \%$ patients and underestimated it in $81.08 \%$ patients. Clinical examination overestimated axillary lymph node size in $27.78 \%$ patients and underestimated in $52.78 \%$ patients. Sonological examination overestimated axillary lymph node size in
$27.78 \%$ patients and underestimated in $72.22 \%$ patients.

In the study of Apple et al [19] clinical examination overestimated tumor size in $67 \%$, underestimated in $26 \%$ and predicted accurately in $7 \%$ patients. An accuracy of $\pm 1 \mathrm{~cm}$ in $66 \%$ of patients by physical examination, $75 \%$ by ultrasonography, and $70 \%$ by mammography has been obtained in comparison to pathological breast tumour size [20]. Compared to the pathologic results, sonography has been shown to underestimate the extension of the residual disease but it was statistically not significant $(r=0.571$, $P=0.0267$ ) [21].

In the present study, a strong correlation with pathological tumour size was observed for primary tumour size estimation by clinical method $(\mathrm{n}=37, \mathrm{r}=.719, \mathrm{p}=<.001)$. Moderate correlation was found for sonology $(\mathrm{r}=0.601 ; \mathrm{p}=<.001)$.

Moderate correlation between pathological and clinical size $(\mathrm{n}=51, \mathrm{r} 2=0.68, \mathrm{P}<0.0001)$ and close correlation with pathological tumour size was observed for ultrasonographic $(\mathrm{n}=52, \mathrm{r} 2=0.89, \mathrm{P}<0.0001)$ tumour size measurement [11]. Physical examination demonstrated the highest correlation coefficient $(r=.759)$ with histopathological size in measurement of the tumour size 
while high resolution duplex ultrasonography has been shown to be the most sensitive assessment method of axillary lymph node status [22]. MRI was a more accurate imaging study at baseline for T3/T4 tumor and physical examination (PE) correlated best with pathology finding while baseline PET and (PE) were shown to be more accurate and sensitive in predicting the final nodal status than the post-neoadjuvant evaluation by either PE or PET, but none was sufficient to replace pathological staging [23].

In the present study, the difference between mean size estimated by clinical and histopathological method for breast tumour was $0.01 \mathrm{~cm}$, which was statistically not significant $(\mathrm{t}=.064, \mathrm{p}=.949)$. However, the difference between mean sonological and histopathological size of breast tumour of $1.10 \mathrm{~cm}$, was statistically highly significant $(\mathrm{t}=-3.93, \mathrm{p}<.001)$. For axillary lymph nodes, the difference between mean clinical and histopathological size was $0.46 \mathrm{~cm}(\mathrm{p}=0.007)$ as against the difference in mean size of $0.48 \mathrm{~cm}$ between sonological and histopathological assessment $(\mathrm{p}=0.001)$.

Neoadjuvant chemotherapy is a well-established modality of treatment in locally advanced breast cancer. It offers a definite advantage by down staging the tumor, thus allowing less extensive surgery. It also improves survival in chemoresponsive patients and provides better quality of life. Imaging modalities like mammography, ultrasound, computed tomography, magnetic resonance imaging and radioisotopes are used for evaluation of chemotherapeutic response in breast tumour [24, 25]. The aim of imaging during and after neoadjuvant therapy is not only to document and quantify tumor response (morphological information and evaluation of residual disease), but also to try to predict the pathological response early after the initiation of treatment (neoangiogenesis and physiopathological tumor activity). As the pathological response of primary breast cancers to neoadjuvant chemotherapy is a surrogate marker for patient outcome, a major impact on survival is only observed in the patients who achieve a pathologically complete response after surgery [26].

Doppler sonography showed high sensitivity for predicting complete histologic response [1, 27, 28]. Decreased tumor vascularity at the end of treatment indicates good response, whereas increased or unchanged vascularity indicates no response [29, 30]. Patients with an intratumoral blood flow velocity increase after chemotherapy had a greater likelihood of local recurrence and metastasis compared with patients in whom flow velocity decreased after chemotherapy [31]. In $40 \%$ of patients, the Doppler changes appeared four weeks before a size reduction was detectable using B-mode ultrasonography [29]. Thus, Doppler flow imaging can be helpful in both assessing and predicting the response of breast cancer to medical treatment. An early decrease or disappearance of tumor vessels may reflect the efficiency of chemotherapy before any decrease in tumor volume.

In the present study, clinical response showed substantial agreement and weakly positive correlation with histopathological response in breast tumour $(\mathrm{k}=0.657$, $\mathrm{p}=0.001 ; \quad \mathrm{r}=0.336 ; \quad \mathrm{p}=0.11) \quad$ while sonology showed moderate agreement and weakly negative correlation $(\mathrm{k}=0.510, \mathrm{p}<0.02 ; \mathrm{r}=-0.18 ; \mathrm{p}=0.39)$. In axillary lymph nodes, substantial agreement and weakly negative correlation $(\mathrm{k}=0.62, \mathrm{p}<0.005 ; \mathrm{r}=-0.020 ; \mathrm{p}=0.94)$ has been found between clinical and histopathological response, while Substantial agreement and weakly positive correlation $(\mathrm{k}=0.691, \mathrm{p}<0.001 ; \mathrm{r}=0.303 ; \mathrm{p}=0.19)$ has been found between sonological and histopathological response.

In the study by singh et al [15] moderate correlation and fair agreement was found between the clinical response grade and histopathologic response grade $(\mathrm{r}=.65, \mathrm{p}<0.001$; $\mathrm{k}=.25, \mathrm{p}<0.0183$ ) in breast tumour. However, Chagpar et al [20] found a poor agreement $(\mathrm{k}=0.24-0.35)$ between clinical and pathologic measurements. The concordance between histopathologic results and color Doppler US was 0.87 vs. 0.474 for clinical examination using Kappa statistics [32].

The greater the shrinkage of the tumor with chemotherapy, the lower the RI $(r=0.70, p=0.078)$. The decrease in RI with chemotherapy, which means increased blood flow at diastole of the cardiac cycle into the tumoral tissue, may be related to decreased intratumoral pressure secondary to tumor shrinkage and may reflect a new type of response, that is vascular response [33]. However, in the present study this type of correlation was not observed $(\mathrm{r}=$ -.273, $\mathrm{p}=.208$ ) in breast tumour, but moderate positive correlation was observed between the percentage change in $\mathrm{RI}$ and percentage change in sonological axillary lymph node size $(\mathrm{r}=0.468, \mathrm{p}=0.021)$.

In the present study, moderate agreement and weakly positive correlation $(\mathrm{k}=0.489, \mathrm{p}<0.02 ; \mathrm{r}=0.089 ; \mathrm{p}=0.68)$ has been found between RI response and histopathological response in breast tumour. Like wise for PI and Vmax also moderate agreement and weakly positive correlation has been found $(\mathrm{k}=0.510, \mathrm{p}<0.02 ; \mathrm{r}=0.16, \mathrm{p}=0.46)$ and $(\mathrm{k}=0.448, \mathrm{p}<0.05 ; \mathrm{r}=0.044, \mathrm{p}=0.84)$ respectively. In axillary lymph nodes, substantial agreement and weakly positive correlation $(\mathrm{k}=0.622, \mathrm{p}<0.005 ; \mathrm{r}=0.090 ; \mathrm{p}=0.75),(\mathrm{k}=0.623$, $\mathrm{p}<0.01 ; \mathrm{r}=0.033 ; \mathrm{p}=0.91)$ and $(\mathrm{k}=0.606, \mathrm{p}<0.005 ; \mathrm{r}=0.028$; $\mathrm{p}=0.92$ ) has been found between RI, PI and Vmax response and histopathological response respectively.

In breast tumour, Singh et al [15] found a significant correlation and fair agreement between RI and Vmax response grade and histological response $(\mathrm{r}=0.688, \mathrm{p}<0.001$; $\mathrm{k}=0.251, \mathrm{p}<0.0002)$ and $(\mathrm{r}=0.675, \mathrm{p}<0.001 ; \mathrm{k}=0.406$, $\mathrm{p}<0.0012$ ) respectively, but a significant correlation and slight agreement between PI response and histological response $(\mathrm{r}=0.751, \mathrm{p}<0.001 ; \mathrm{k}=0.123,<0.716)$.

Based on the color Doppler findings, a new scoring system was proposed that could predict histological response following chemotherapy. Higher scores corresponded with a more favourable histopathological response. $66.7 \%$ patients had a cumulative Doppler score more than nine. The cumulative Doppler scores were correlated with histopathological grades of response and found to be statistically significant $(p<0.05)$ [16].

In the present study, $83.33 \%$ showed a Doppler score of 
3-5 for breast tumour following chemotherapy. Doppler score between 10-12 in the breast tumour was not observed in this study. In axillary lymph nodes, $54.17 \%$ patients showed a Doppler score of 3-5 for axillary node following chemotherapy. Doppler score between 10-12 was observed in $29.17 \%$ patients. The agreement between Doppler score and histopathology response was found to be moderate in breast tumour as well as in axillary lymph node. However, it was more significant in axillary lymph nodes $(\mathrm{k}=0.562$, $\mathrm{p}<0.01 ; \mathrm{k}=0.469, \mathrm{p}<0.05)$.

\section{Conclusion}

In the present study, sonology was found to be a poor modality for breast tumour size and axillary lymph node size estimation. With regard to chemotherapy response assessment, clinical examination was a better modality for primary, while Colour Doppler was better for axillary lymph node evaluation.

\section{References}

[1] Veronesi U, Galimberti V, Zurrida S, Pigatto F, Veronesi P, Robertson C, Paganelli G, Sciascia V, Viale G. Sentinel lymph node biopsy as an indicator for axillary dissection in early breast cancer. Eur J Cancer 2001;37:454-8.

[2] Cowen D, Jacquemier J, Houvenaeghel G, Viens P, Puig B, Bardou VJ, Resbeut M, Maraninchi D. Local and distant recurrence after conservative management of 'very low-risk' breast cancer are dependent events: a 10-year follow-up. Int J Radiat Oncol Biol Phys 1998;41:801-7.

[3] Dongen van JA, Bartelink $\mathrm{H}$, Fentiman IS, Lerut $\mathrm{T}$, Mignolet F, Olthuis G, Schueren van der E, Sylvester R, Tong D, Winter J, et al. Factors influencing local relapse and survival and results of salvage treatment after breastconserving therapy in operable breast cancer: EORTC trial 10801, breast conservation compared with mastectomy in TNM stage I and II breast cancer. Eur J Cancer 1992;28A(45):801-5.

[4] Carter CL, Allen C, Henson DE. Relation of tumor size, lymph node status, and survival in 24740 breast cancer cases. Cancer 1989; 63: 181-7.

[5] Sobin LH, Wittekind C. TNM Classification of malignant tumours, Breast Tumours (ICD-O C50) 1997.

[6] Critical assessment of the clinical TNM system in breast cancer. Report from the Yorkshire Breast Cancer Group, Br. Med. J. 1980; 281: 134-6.

[7] Hortobagyi GN. Developments in chemotherapy of breastcancer. Cancer 2000; 88 (Suppl-12):3073-3079.

[8] Bonadona G, Valgussa P, Brambilla C, Moliterni A, Zambetti M, Ferrari LS. Adjuvant and neoadjuvant treatment of breast cancers with chemotherapy and endocrine therapy. Semin Oncol 1991; 18: 515-24.

[9] Smith IE, Powel TJ, Martin Dunitz. Medical management of breast cancer primary medical therapy. London 1991; 259.

[10] . Dixon JM, Senbanjo RO, Anderson TJ, Forrest AP, Elton
RA: Clinical assessment of tumour size in primary breast carcinoma. Clin Oncol 10:117-121, 1984.

[11] Forouhi P, Walsh JS, Anderson TJ, Chetty U: Ultrasonography as a method of measuring breast tumour size and monitoring response to primary systemic treatment. BrJ Surg 81:223-225, 1994.

[12] Fornage BD, Toubas O, Morel M: Clinical, mammographic, and sonographic determination of preoperative breast cancer size. Cancer 60:765-771, 1987.

[13] Dixon JM, Walsh J, Paters M, Chetty U. Color Doppler ultrasound studies of benign and malignant lesions. $B r J$ Surg 1992; 79: 259-60.

[14] Kumar Anand, Srivastava Vivek, Singh Seema \& Shukla RC. Color Doppler ultrasonography for treatment response prediction and evaluation in breast cancer. Future Oncology 2010; 6(8): 1265-1278.

[15] Singh S, Pradhan S, Shukla RC, Ansari MA, Kumar A: Color Doppler ultrasound as an objective assessment tool for chemotherapeutic response in advanced breast cancer. Breast Cancer 2005, 12:45-51.

[16] Kumar A, Singh S, Pradhan S, Shukla RC, Ansari MA, Singh TB, Shyam Rohit and Gupta Saroj. Doppler ultrasound scoring to predict chemotherapeutic response in advanced breast cancer. World Journal of Surgical Oncology 2007, 5:99.

[17] Nair MK, Varghese C, Swaminathan A. Cancer: Current scenario intervention strategies and projections for 2015 . Burden of disease in India. Background papers. National Commission for Macroeconomics and health, Ministry of Health and Family Welfare, Government of India, New Delhi. Pp. 218-25, 2005.

[18] Veronesi U, Cascinelli N, Greco M, et al. Prognosis of breast cancer patients after mastectomy and dissection of internal mammary nodes. Ann Surg. 1985; 202:702-707.

[19] S.K. Apple, F. Suthar. How do we measure a residual tumor size in Histopathology (the gold standard) after neoadjuvant chemotherapy? The Breast 2006; 15: 370-376.

[20] Chagpar A, Middleton L, Sahin A, et al. Accuracy of physical examination, untrasonography, and mammography in predicting residual pathologic tumor size in patients treated with neoadjuvant chemotherapy. Ann Surg 2006; 243 : 257-264.

[21] Viviana Londero, Massimo Bazzocchi, Chiara Del Frate, Fabio Puglisi, Carla Di Loreto,Giuliana Francescutti, Chiara Zuiani: Locally advanced breast cancer: comparison of mammography, sonography and MR imaging in evaluation of residual disease in women receiving neoadjuvant chemotherapy. Eur Radiol 2004; 14:1371-1379.

[22] Cheong Shook Lee, Jin-Gu Bong, Jin-Hyun Park, Yoon Sik Lee, Sun-Mi Paik, et al., The accuracy of the physical examination, mammography and ultrasonography in the assessment of tumor size and axillary lymph node metastasis in breast cancer patient serve as use adjuncts to sentinel node biopsy. Journal of Korean Breast Cancer Society 2003; 6: 87-94.

[23] Raquel Prati, Christina A. Minami, Jeff A. Gornbein, Accuracy of Clinical Evaluation of Locally Advanced Breast Cancer in Patients Receiving Neoadjuvant Chemotherapy. Cancer. 2009; 115(6):1194-1202. 
[24] Sabel M, Aichuinger H: Recent developments in breast imaging. Phy Med Biol 1996; 41:315-368.

[25] Kubota K, Hisa N, Ogawa Y, Shoji Y: Evaluation of tissue harmonic imaging for breast tumors and axillary lymph nodes. Oncology Rep 2002; 9:1335-1338.

[26] Newman LA, Pernick NL, Adsay V, et al: Histopathologic evidence of tumor regression in the axillary lymph nodes of patients treated with preoperative chemotherapy correlates with breast cancer outcome. Ann Surg Oncol 2003; 10:734739.

[27] Caruso G, Cucciarre S, Lo Bello M, Mercurio G, Candela F, Cianchino C, Lagalla R. Neoadjuvant intralesional chemotherapy for breast neoplasm in advanced stage. Assessment of its efficacy with Doppler color. Radiol Med (Torino) 1995;89(5):613-618.

[28] Lagalla R, Caruso G, Finazzo M: Monitoring treatment response with color and power Doppler. Eur J Radiol 1998; 27(Suppl 2):149-156.

[29] Kedar RP, Cosgrove DO, Smith IE, et al. Breast carcinoma: Measurement of tumour response to primary medical therapy with color Doppler flow imaging. Radiology 1994;
190(3): 825-30

[30] Roberrto L, Giuseppe C, Mario F. Monitoring treatment response with color and power Doppler. Eur J Radiol 1998; 28: $\mathrm{S} 149-156$

[31] Singh Gurpreet, Kumara Pratik, Parshadb Rajinder, Seith Ashu, Thulkar Sanjay, Hostend Norbert. Role of color Doppler indices in predicting disease-free survival of breast cancer patients during neoadjuvant chemotherapy. European Journal of Radiology 2009.

[32] Huber S, Medl M, Helbich T, Taucher S, Wagner T, et al: Locally advanced breast carcinoma: Computer assisted semi quantitative analysis of Color Doppler ultrasonography in the evaluation of tumor response to neoadjuvant chemotherapy. J Ultrasound Med 2000; 19:601-607.

[33] Berna Öksüzoğlu, Murat Vural, Hüseyin Abalı, Mesude Yılmaz, Nuriye Yıldırım, Nurullah Zengin. Blood Flow Indices by Doppler Ultrasonography Vary with Neoadjuvant Chemotherapy but Are Not Related to Plasma VEGF Levels in Locally Advanced Breast Cancer. Oncology 2006; 71: 185-189. 